\title{
A visual approach to poetry analysis
}

\author{
Shamal A. Hussein ${ }^{1}$, Mariwan N. H. Barzinji ${ }^{2}$ \\ ${ }^{1}$ Department of English, University of Human Development, Sulaimani, Kurdish \\ ${ }^{2}$ Department of English, School of Physical and Basic Education, Faculty of Basic Education, University of Sulaimani, Kurdish
}

\section{Email address:}

shamalinternet@yahoo.com (S. A. Hussein),mariwan152@live.com(M. N. H. Barzinji)

\section{To cite this article:}

Shamal A. Hussein, Mariwan N. H. Barzinji. A Visual Approach to Poetry Analysis. International Journal of Literature and Arts. Vol. 2, No. 2, 2014, pp. 49-59. doi: 10.11648/j.ijla.20140202.15

\begin{abstract}
To help students find delight and rational inspiration in verse, teachers might utilize numerous methods. Firstly, an introduction may be given on the course by expressing aims and processes, and by questioning students about to what extent they think reading and studying poetry is significant. The lecturer must engage the entire students, particularly the reluctant students; the technique of visualizing of imagination, a number of poems to them and letting the students look till they see the exact link between the text and the images; the images are not alone but the overall scene consists of separate images and symbols, this is what can be seen as one of the significant outcomes of this approach and then they enjoy it. After that, each student can understand the poem via this technique. Then the teacher may read the poem and show the images that can explain the poem, at the same time. This will facilitate the difficult task of the students. This procedure supports students to learn the traditional things teachers explain about poetry, such as the terms, symbols, and kinds of poetry, though time providing pleasure for the student simultaneously.
\end{abstract}

Keywords: Tasting and Testing Poetry, Teaching Poetry in the Age of Technology, Visualization

\section{The Hypothesis Diagram}

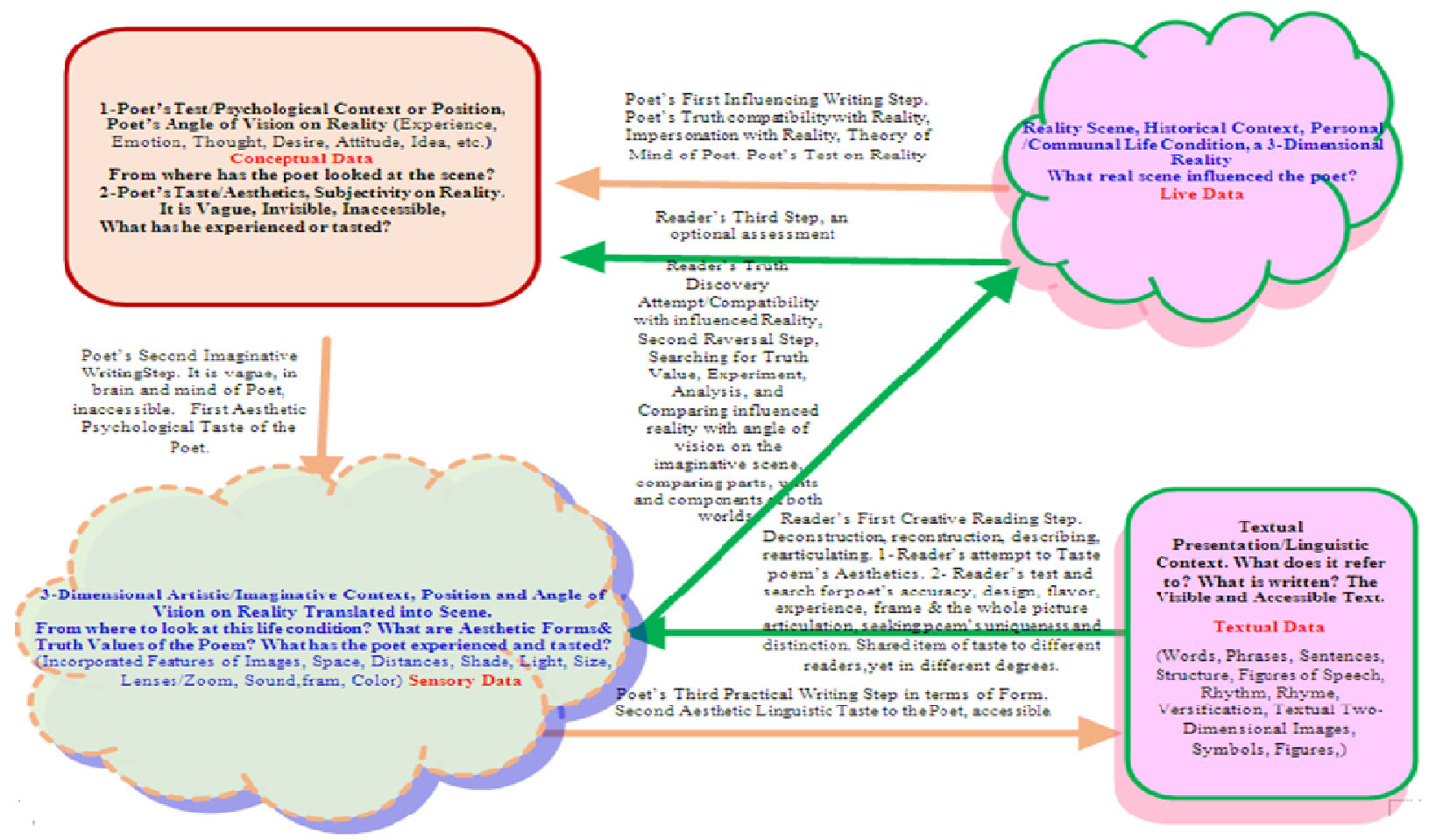




\section{The Way of Poetry}

Research questions are more relevant to the pedagogical context based on poetry teaching goals and its methodology outline, inspiring students in classrooms to have access to and appreciate poetic analysis, truth and aesthetics. Those questions would beinquiries like what follows:

Is there any difference between testing and tasting poetry? Do poets and readers have the same access to poetic test and taste? Are poet's angle of vision and his ideas different? If poets and readers experience the same positions and location standpoint, are they going to have the same experience? Can we experience and/or experiment poetry?

This study aims at improving the pedagogical situation of literary studies in the classroom, motivating "hunting for books that will renew a focus on our engagement with art"1 which is an instant academic and cultural need, to make best results of teaching and reading poetry, and to go inside humanity and make use of digital humanity. It is to personalize learning; not only the mind or skills, but also indulging feeling and senses with teaching, as an integrated approach of teaching and learning, as an exploratory model with students. It gives an opportunity to readers to practice creative reading, drawing, and thinking, as an imaginative pleasing game, exercise, and training, all the way through poetic analysis.

The study is an experiential and experimental model explored with students, assessing their educational needs and enhancing their critical thinking and close reading competences, offering analytical tools to readers and students, training them on constructing, integrating and incorporating skills they may develop later more effectively. It tries to deal with the literary problem of entering the world of poetry. It is more about what to do with what is there in the text, more than what to put in the mind of students or readers, producing more questions and offering space for producing more accurately driven answers, in a set of consecutive activities, supported by a clarifying interdisciplinary diagram.

Initially, this project has been inspired by different disciplines and fields of study, rather than by specific writers or trends. It is the result of an ongoing interaction and internal discussion between our academic scientific and literary background with students, I as a mechanical engineer, studying and loving Math and Physics, accompanied by another academic, yet literary, background in English literature as graduating and studying a master degree in English literature, and finally self-educational attempts on psychology and teaching experience for more than 17 years and my colleagues experience in teaching poetry for more than 5 years also enriches this work. However, some writers influenced this poetic analysis study, although they were not necessarily writing in the field of literature, like Ali Izzat Bigovitch, Chomsky, Albert
Einstein, Phillip Sidney, Sartre, Socrates, Shakespeare and Freud. Class discussion with students for about 5 years was the main inspiring reference and motivation to rethink about poetry, poetic function and analysis from other points of view, as well.

As an introductory step, this research assumes that it is possible for a poetic analytic strategy to exceed the diverse classifications of the literary approaches, such as economic, feminine, psychological, textual, if it starts with the scope of textual and sensory data given in a poetic work. Those approaches would start with certain orientations they suggest, which are basically not framed by the type of the given data, but by the approaches' thematic sections. It can be argued that the thematic presupposition and segregation would imply that a studied poem must have some thematic relation with an applied approach and it must let the approach to be applied on it. Thus, when applying a specific literary approach, it would exclude some data that may not be relevant to its orientationor thematic framework, which may still be important to understand the poem or to evaluate the aesthetic merit of the poem.

This research examines the nature and structure of poetry, as an imaginative alternative context or scene to the real world influenced the people's life condition, individually and/or socially, which the poet indirectly views and experientially lives. It also addresses the way in which readers can comparatively live or share the poet's angle of vision without necessarily being occupied by the poet's ideas, feelings, or attitudes. The poet will be privileged to have different what we call "tests and tastes" throughout the versification process. He tests the influence of reality upon him from the angle of vision he has on the reality, before writing anything, either. Then, the poet tastes what some may call "inspiration", i.e. transforming his angle of vision into an imaginative scene, enjoying the first-hand taste of this transformation, which is subjective as a psycho-neurological process in the poet's personality that readers have no access to, at least yet. Both those test and taste are deeply mental from the part of the poet. The second taste the poet experiences is when he transforms the imaginative scene into a textual writing in the body of the poem. This taste is shared by the reader when the reader tries to step back and re-articulate the scene from a given poetic text, in terms of its linguistic structure, figurative language, and imagery. Accordingly, it becomes apparent that the poet experiences two aesthetic tastes from which only one is shared by the reader. This is a difference between poets and readers in terms of the taste, i.e. between producing (writing) and studying (reading) a literary work.

The poet transforms the reality he experienced for a while to the reader, indirectly, by bringing and mediating an imaginative scene between his life experience and his language, poem, or textual form. The poet tries to find equivalent or appropriate words for images to create a scene, rather than trying to derive words for abstract concepts, ideas and emotions. This can be regarded as a 
difference between poetic and other types of presentation, like philosophical, scientific, journalistic, historical texts, because the latter fields try directly to touch upon certain ideas, thoughts and feelings without using an indirect medium. This approach will put the poet away from the poetic reading, focusing more, instead, on the reader as the most essential part of the reading process. The poet almost functions as a mediator, as a correspondence between two worlds, i.e. living world and the imaginative scenario in the poem, to encourage or intimidate readers to empathetically communicate and compare those two versions of life. The study supposes that when the poet first saw that real life condition, the reader was not there, or is not aware of it, still. That's why the reader would try to live instantaneously with/within the text or the scene, interacting with the poem itself, rather than reading about it, using interdisciplinary tools of reading like (Text - Scene Psychological Position). The different contexts or phases of poetic analysis can be categorized according to the nature and function of the data they provide. Thus, the approach differentiates four types of presentations or scopes of data;

1. The influencing reality, as live data, that can be accessed through the life condition at poem's writing time, and/or the poet's biography.

2. Repleteness, density, context, emotion, feeling, abstracts, attitudes, and thoughts. It is a psychological, mental and conceptual data and context, as intellectual/emotional, experientially woven data, lived by the poet. This data is almost hidden from the readers.

3. Image, property, scene, dimensions, exemplification, and symbol, in the brain. This is an invisible recollected re-articulated sensory data and context, interrelated and sensorily woven, as an aesthetic context, which functions as an alternative imaginative scene to the poet's previous psychological context. It is accessible through imagining the poem's scenario.

4. Words, script, sounds, and letters. It is a given textual data and context, linguistically woven, as a linguistic translation or transformation of the previous imaginative scene, and accessible through textual reading.

On the part of the reader, the reading process includes two reversal creative reading steps. To step backward from the text to the imaginative scene will be the first, as the reader experiments or tests the poet's performance in the linguistic and artistic skills used in writing the poem, which can be regarded as an objective test, shared by many readers. Here, the readers would taste poet's performance also. It will be about the artistic skills used in writing the poem, which can be regarded as an objective taste in terms of the type, category, and item of the aesthetic experience, shared by many readers. Meanwhile, different readers would experience different degrees, densities, and levels of this exact aesthetic tastes and that will be more subjective.

Then the second reversal step is from the scene to the reality. Here, reality would be the personal and social historical context, and/or the poet's biographical situation or life condition when writing the poem. The reader tests, experiments and compares the scene's truth compatibility with reality in terms of where the poet is looking to the reality form, which can be more objective among readers. Moreover, the reader tastes, experiences, and compares scene's aesthetic compatibility with reality in terms of what can be seen at that moment, which is more subjective among readers and they may differ about both the type and degree of this aesthetic experience.

The project deals with an interdisciplinary method that is integrating linguistic-artistic-psychological tools, aiming at impersonating the poet's perspective (position, angle of vision, frame of vision, space of seeing, and distance from the scene), rather than his mentality (personal ideas, feelings, or attitudes).One of the reader's feet is still in reality of human life condition, and the other is in the imaginative scene of the text and poet's world. This will make the reader more empathetic, to "feel the heat of [the poet's] creative power"2.

The reader will start the primary creative reading step upon the text by deconstructing its ingredients as raw materials (as a linguistic textual data), to bring back and recall the mental features of the images used in a text, which is shared by both writer and reader, rather than only searching for the metaphoric or denotation meanings of the words in language, to collect and link words, phrases, transforming into images, drawing pictures in a deconstructive way. Mental features of images are more approached in this research rather than merely linguistic meanings of words. Single images are known to the reader. What is new is the scene and relationship between single scattered images throughout the poem. Then, he is visualizing the words (into images and scenes in an imaginative drawing) in reconstructing steps, reaching and reshaping the poets psychological position, and starting comparison, accumulation, searching for aesthetics and truth.

The reader needs to practice a visualizing or visualization creative reading. There are some elements incorporating in the visualization process of remaking the poem's imaginative scene, which are to be discovered by the reader in his creative reading practices:

1- The text images and figures, as the source, components and parts of the ultimate scene, $_{2}$ when the reader asks what is there in the scene, the space given to the poem, as the atmosphere and frame of the scene. How can the text transformed into a scene, and what linguistic skills can be explored?

2- The rate of subjectivity and/or objectivity, as the distance or the indulgence the author keeps in the textual presentation between him/her and the ultimate scene, from which angle of vision should the reader look at the scene, as an objective experimental test?

The reader tries to make the two dimensional images of the text seem as a three dimensional scene, which can be a

\footnotetext{
${ }^{2}$ (1) Literary Aesthetics: the Very Idea. Lindsay Waters.December 16, 2005
} 
fixed or an animated video scene. The practice is more about where the poet looks at the scene, as if he is a cameraman. The scene here is not a photographic picture inside the studio, but it is an almost natural scene in a living space that gives more details. In the poetic text, poets usually tell the readers where to look, which is a part of the poem's objectivity, but what to see is something left to the creativity of the readers and it is a part of the poem's subjectivity.

The approach deals reader's analytical attempt even before getting in touch with any previous critique about an exact work. The nature of the result would be a first fresh and native encounter of the reader with the text, where creativity may emerge, untouched by lots of critical backgrounds and ideas. It does not mean that readers cannot make use of such critiques afterward, but it is just a way of giving more space and psychological confidence to the reader to polish, practice and promote their curiosity and critical abilities. It can be said that this approach is based on and counts for the scope of poetry, which specifies the materials and data that can be regarded as poetic, more than orientation of poetry, which specifies the path and ultimate value of poetic works. Thus, the result of poetic reading according to this approach will be a discovery by the reader and it will be an open ended practice for readers.

Humanity truth in poetry is different from scientific truth While scientific truths may be more laboratorial as humanto-something relationship, poetic truth turns to be a more psycho/social universal truth, human-to-human hood and even a someone-to-himself relationship. In a scientific scene, the images, abstractions, and words are controlled variables in a limited laboratory space. Here, the variables cannot talk about themselves, but the examiner talks on behalf of them directly, without any mediating scene. However, in a poetic scene, the images and words are freer variables, less controlled, in a limited natural space, where the freer variables talk about themselves indirectly by the means of a mediating alternative imaginative scene. While science's language implies what is said clearly, poetry's language implies what is not said, either.

The research presupposes that each literary work has got a theory, argument or order, although it may not be in the same logicality one may find in philosophical, legal or scientific writings, because the nature of the stories and the proofs would be different, here. Poetry's holistic humanitarian nature and experience appeal to experiential proofs shared by the poet and the readers more than merely logical experimental partial evidences. That's why this research deals with the theory of a poem, rather than the ideas in mind of a poet. It is also an important and applicable approach in literary teaching, human development, and creative writing training courses as well. In visualizing practices, "readers create mental images, they engage with text in ways that make it personal and memorable to them alone. Anchored in prior knowledge, images come from the emotions and all five senses, enhancing understanding and immersing the reader in rich detail. [It] increases the ability to elaborate on characters, scenes, actions, and ideas, [heightening] enjoyment of reading, [helping] in solving problems in math, process descriptions, [improving] test scores on various reading measures, including standardized tests.[It has also] been successful in improving comprehension monitoring, a skill integral to expert reading, identifying main ideas and justifying these with evidence from a text, and seeing patterns of details across a text or texts to discover complex relations. Recent NAEP studies show that fewer than six percent of our high school seniors can effectively use these skills." ${ }^{3}$

The practice of visualization or visualizing can be explained, as "you muse over a poem, read a novel, or pause over a newspaper story, a picture forms in your mind. Certain smells, tastes, sights, and feelings emerge, depending on what you're reading and what life experiences you bring to it. Information comes to you through your senses. This technique triggers a wide range of memories and feelings.[It is] like you're in the book, but you're invisible and you're watching everything but the characters don't notice you. Sensory images are like a movie in your head, but if you're just reading words, you won't get a movie in your head, so you have to reread. Sensory images make reading a lot fun. If you're reading and then take your eyes off the words, you will say 'What's happening?' And then if you reread, you will get your movie back, but if you keep reading, you won't get your movie back." ${ }^{4}$ However, this research wants to go a step beyond visualization. It attempts reintegrating the whole scene, not only imaging words or visualizing reading, which has been dealt with in more details in the research methodology.

Test and objectivity deal more with how much space is given to the scene, the distance from the scene, and the standpoint. However, how the reader perceives, sees, feels, and thinks about the poem can be subjective or may reach levels of objectivity and they are a matter of taste. This approach tries to go inside the scene, where the poet was sitting or standing, seeing things, dreaming, and inspired, to see whether what the poet describes, sees, and says are the same to the reader, or different, when being in the same position. When the reader is led into the poet's position, distance, space, angle of vision, zoom, and latitude, he may doubt or accept the degree of the taste that the poem suggests.

The truth credentiality of the poem and the poet relies in the compatibility level, consistency or accuracy they achieve in presenting and mediating an imaginative scene to the life condition influenced the poet. As an item, the poet and the reader can experiment the same couple of truths. When the testing process is conducted by the reader, the first would be the text-scene compatibility test, trying to

\footnotetext{
${ }^{3}$ (2)http://www.powershow.com/view/214ea7MmU5M/Visualizing_powerpoint _ppt_presentation
} 
describe and reshape the scene presented in the text. And the second is the scene-reality compatibility test as a more analytical process, comparing both those worlds, questioning levels of accuracy in presenting the scene, and mediating between the scene and reality. Here, different readers in the latter test may not necessarily have the same degree or dense of experience, although they will be sharing the same type, category or item of experience, and this is what would make readers different among themselves about poetic reading.

Aesthetics comes when the poet tries to attract people to convince them that what he says is true. Then, aesthetics are tools and baits of truth hooks, to catch the reader's attention, or to let the reader be caught by the truth, and the reader may be seduced by aesthetics without finally ending with any truth, or may end with a lie, as Socrates would have argued. But this approach lets reader to get to the potential theory or truth of the poem without being caught by hook of aesthetics, letting him eat the bait safely, tasting it, getting to be sure whether it was a hook or something else, and testing the logic of the hunting behind it, without getting hurt, as the reader puts a foot inside, and keeps a foot outside the text.

Poets usually write in a figurative way that covers the truth value of the poem, attracting readers to the partial pieces of beauty scattered here and there throughout the poetic writing, which sometimes deviate and prevent readers from seeing the overall aesthetic scene or the truth value underneath the beautiful cover of the text. This research is an attempt to make the overall scene and potential truths accessible, to test and taste whether they are credible in the way the poet would have expected, or how would it turn to be.

In a more visualized world and globe, in an age of information technology revolution, we need to find ways of visualizing teaching and learning, more. This research aims at achieving a practical level of such a need. On one hand, it aims at providing a literary critical approach "to appreciate aesthetics - to study how human beings respond to art" , besides searching for the literary truths, bringing up critical readers, and creative writers, as well. On the other hand, the project premise does not promote "the senses and emotion over reason and ideas", searches for ways of making them complementary. Although in "the 1980s and 90s, scholars like Terry Eagleton blasted away against the idea that the arts were autonomous no longer as Sir Philip Sidney and Percy Bysshe Shelley had declared to be encountered on their own terms" 7 , this research scrutinizes whether they are autonomous or rather different types of truth and experience, that can be shared by poets and readers, to point "to the democratic potential of a revival of aesthetics." 8 The research helps at exploring emotional subjective aesthetics, besides shared objective logical value of poetry. It is not a kind of analysis that would "continue to shuck text of its form, reducing it to a proposition to be either affirmed or denied, the way a farmer shucks an ear of corn. When they're done interpreting a poem, what is left of the poetry?" ${ }^{9}$ Here, understanding poetry does not mean practicing separation, or destruction, and there are no extra pieces in poems that are not needed. It is more a kind of evaluation process rather than separation, and the poem remains as it is, a scene or picture. It is a scenario script, to be examined as one holistic piece of work. That is why the poetic writing can be touched upon as a woven work, in terms of both form and content. There is less chronology in poetic structure and it has a space-bounded order, rather than being a time-bounded one.

Sometimes the poet as a mediator will be an unbiased writer, sometimes biased, narrowing the vision and the space of seeing and intentionally directing the vision that would marginalize some other scenes, images and elements. He may turn his face away from a truth that has to be spoken about. Poet's intention and orientation is disputable, whether he is a self-interested conservative or he is benevolent to the public issues, whether he seeks public for his own favor or he sees himself in the favor of his public context. The text is a nature, a land of raw materials, the scene is an objective entity. He, subjectively or objectively, makes use of that nature, land or materials and composes his poem with certain potential truth values and aesthetic. This is an area that can be studied in the future as the relationship between poet and value system related to the ethics, responsibility, challenges, and promises of being a poet, upon individuals and community as well.

It can be argued that this study is different from the approaches that may reduce "a text to its historical and moral significance" [that] has nothing to do with aesthetic responses to art, [but] only with conscious acts of will. Nothing is to be left up to the senses, to the emotions." 11 It deals with "What Meaning Cannot Convey"12. It aims at exploring what else besides word's meaning is to be drawn. Here, the "key is [not] to think" ${ }^{13}$ only, but rather to meditate during the reading process in the imaginative scene drawn by the poet, and it is "about how we experience it." 14 It does not present a two-dimensional photographic picture, fragmented images or entities, as representation of single ideas, but rather it produces a three-dimensional integral scene.

Didactically speaking, this approach is an integrating attempt, because it gives access to knowledge and into feeling as well, to teach and please, going beyond the

\footnotetext{
${ }^{8}(1)$

${ }^{9}(1)$

${ }^{10}(1)$

${ }^{11}(1)$

${ }^{12}(1)$

${ }^{13}(1)$

${ }^{14}(1)$
} 
textual surface of the poem.

\section{Further Relevant Topics}

There are some relevant topics that have to be studied in this project, like:

- Relationship between dream, poetry and scene. Text, poetry writing and vague areas of writing poetry, in terms of vagueness and transparency

- Current status of critical debates of form and function of poetry

\subsection{The night is darkening round $m e^{15}$ By Emily Brontë 1818-1848}

The textual data and words used to extract the sensory data for the sake of featuring the imaginative scene can be read as follows, which can be regarded as the steps traced throughout the other poems studied here in this research;

1- The words will be seen as images and sensory entities.

2- The features of those images and sensory entities will be elaborated, rather than merely their meaning as words. The overall space and scene, and the relationships between separate images and their features will be examined.

3- A comparison will be drawn among different experiences of the character throughout those three stanzas, or parts of the poem. Any similarities, differences, decline, and/or progress will be traced.

4- A comparison will be drawn between this imaginative scene and reality and historical life condition of this character as a woman at that historical context.

5- The conclusions will be drawn.

The key words and images are (darkness, me, loneliness, blowing wind, inner spell, lacking ability to move, giant tree, bearing snow, blowing storm, still lacking ability to move, clouds everywhere, wastes everywhere, nothing can move her, she has willpower now, she decided not to move, and she cannot move or leave because she committed to stay). The final conclusion is that she discovered her weakness and strength. She impersonated the giant tree, she is now a tree. So, she will not and cannot move from now and on, any more, and even nothing can move her, either.

Here is the line by line visual analysis;

The night is darkening round me

The wild winds coldly blow

But a tyrant spell has bound me

And I cannot, cannot go

The giant trees are bending

Their bare boughs weighed with snow

The storm is fast descending

And yet I cannot go

Clouds beyond clouds above me
The poet starts with the setting; (the time is night and it is dark but it gets darkening more and more as a visual element vanishing the sight and transparency, it is round ME, the focus is on ME, and I have only myself with me, so I am alone and it is hard to be alone in darkness, and even I cannot see my "ME" or my inner self, clearly

(wind is wild, it does not know me, does not care, and brings cold wind, as an auditory element it brings more hardship to the darkness and my loneliness, so visually and auditorily I am in threatened, and this the physical space given to me

(BUT there is something more problematic for me than the external visual and auditory elements round me, a dominant internal spell has bound me, preventing me from movement, from seeing myself, or trying any even intellectual move from my position as a young female

(I have the reason not to be able to go, there is a reason for my pause, bodily and mentally I am obliged to stay where I am

(The only move I can do is looking at outside. I want to see how the external elements affect other things than ME, the focus here is on other elements undergoing the same scene and atmosphere. The cold wind affects the surrounding, giant trees, with their giant roots and boughs, are bending, yet don't break, so they bear, survive or sustain under the external impact because of their internal strength, i.e. their deep roots in the space or ground they live on

(they are bare, no fruit, no leave, no beauty, no living remark like greenness, weighed with heavy snow, cold and white. They have many features common with me, we share lots of traits and our life condition or experience is somehow alike, we undergo similar external situations and we have internal similar life condition, like being bare, no fruits, no leaves, no beauty, no living remarks or qualities like greenness or hope. Here she starts a comparison between the trees and herself, at least she has a close sample to be compared to understand her situation better through.

(the trees are suffering like me with storm, fast and descending, like wind blowing round me (those are different, the trees bear the white snow, and the fast storm, but I am not like them in surviving and struggling against the external influence, because I don't enjoy the same internal strength

(now, one more time she goes back to herself, the focus is on herself once more. She embodies herself

\footnotetext{
${ }^{15}$ Poets of the English Language (Viking Press, 1950)
} 
Wastes beyond wastes below

But nothing drear can move me

I will not, cannot go in the tree, like its boughs weighed with snow, her body is weighed with piles and piles of cloud, clouds in a dark night, may be dark clouds as well, as a symbol for different external sources of darkness round her and above her, as if imposed on her, or as if this is the source of fear feeling and weakness binding me as an internal tyrant spell

(bellow and beyond me there are wastes, above, below and beyond in all directions, I am surrounded with spell, darkness, waste, clouds, wind, and coldness, just like the trees, as if they are the roof, walls, and the ground I am living in as a house or room

(BUT no external scary power can move me, I have come to a moment of self-recognition about my weakness as physically and mentally not being able to move. Now I decide physically not to go or move, my mental power is that I will not move from my space, but stay and start my struggle form here

(I regained my willpower and decision making ability, and I decide not to go but stay, it is not fair for me to go, I am on my ground just like the tree, so no fear, no move, just patience, and this is the cure for the spell curse on me, this is the self-realization I gained finally, the space of my challenge and opportunity is the same

\subsection{Song (When I am Dead, My Dearest) 1862, by Christina Rossetti, 1830-1894}

The key words and images are (death as chasm and separation between two worlds, body and senses are no more there to feel the world, except feeling her; sound, color, touch of shade do not reach poet's dead body, only your memorable features as tender as grass, moderate as shower, and refreshing as dewdrops can touch his soul underneath. So, it is up to her whether she wants to remember or not, but he will remember her with those features. Once more, he re-affirms that he lost touch to physical world other than her, no more sensory sight, no more feeling tough of rain, no more hearing, no more empathy to other's pain and loneliness, no more sense of time passage without her). The final conclusion is that without living inside and with her memories he would no more exist in anyone's memory, or he would no more feel the world. So, there would be no remembrance, nor forgetting, either.

\begin{tabular}{|c|c|}
\hline When I am dead, my dearest & (death is separation between beloved parties \\
\hline Sing no sad songs for me & (song does not reach me, sound does not reach my ears, I have no ears any more \\
\hline Plant thou no roses at my head & (flower does not reach my eyes, I have no eyes any more \\
\hline Nor shady cypress tree & (no shade would get me, I have no skin any more \\
\hline Be the green grass above me & $\begin{array}{l}\text { (be close, soft, and kind to me, and cover me } \\
\text { (your grass covers me with sweet dewdrops of the morning or in the twilight, with plenty grass hairs, and }\end{array}$ \\
\hline With showers and dewdrops wet & $\begin{array}{l}\text { plenty drops on them, are plenty in number, the only element I want to be close to me from earthly life is } \\
\text { you in the form of green grass }\end{array}$ \\
\hline And if thou wilt, remember & $\begin{array}{l}\text { (If you wanted, please, remember to come and be like that I have imaged and drawn about you, and want } \\
\text { you to be, not other conventional ways of visiting grave yard as I mentioned before. }\end{array}$ \\
\hline $\begin{array}{l}\text { And if thou wilt, forget. } \\
\text { I shall not see the shadows }\end{array}$ & (and if you don't want to remember to be like that, please, forget about it, and it is ok \\
\hline I shall not feel the rain & $\begin{array}{l}\text { (when you are absent from the scene as green grass and you are no more close to me to cover me, I no } \\
\text { more have eyes to see shadows of trees above me, or of clouds on earth, I no more have skin to feel the } \\
\text { rain coming down from clouds, and I feel no raining, no more earthly element would get me }\end{array}$ \\
\hline I shall not hear the nightingale & (when you are absent from the scene as green grass and you are no more close to me to cover me, I no \\
\hline Sing on as if in pain & $\begin{array}{l}\text { more have ears to hear the nightingale singing as if it is in pain as conventional image and connotation of } \\
\text { nightingale and grave and sadness, and no more earthly element would get me }\end{array}$ \\
\hline And dreaming through the twilight & (then, twilight by itself as an atmosphere, when you are absent and without your green grass with \\
\hline That doth not rise nor set, & $\begin{array}{l}\text { dewdrops covering me; is just like a dream to me, I lose sense of time and means nothing to me whether it } \\
\text { rises or sets, or time will stop and makes no change for me as if it does neither rise nor sets }\end{array}$ \\
\hline Haply I may remember & \\
\hline And haply may forget & $\begin{array}{l}\text { (then, in your absence covering me like green grass, I accidently may remember you or anything, because } \\
\text { you are the only link between me and the world, you are the connection and you are the remembrance } \\
\text { itself, and without you I would have no memory, so I would hardly remember the world, though it is hard } \\
\text { for me to forget you }\end{array}$ \\
\hline
\end{tabular}

\subsection{The Sick Rose by William Blake 1757-1827}

The key words and images are (rose as a spatially fixed creature, short time life span, even shorter when being sick, a hiding worm, spatially capable of flying and at large, free in darkness, acquainted with darkness and storm or utilizing them to strengthen his invisibility more. Sneaking and reaching the rose's bed, calmness, freedom, dreamland, safety, comfort, a bed where joy rests in peace and privacy, bed of serious and vital pleasure, associated with blood and life, may be the rose's virginity, his secret tendency and attraction unseen in public buthisdark intention destroyed her life for lust, that's why she is sick now and the poet understands that). The final conclusion is that she as a rose 
and he as a worm do not belong to the same species, he is a plant eater, and however, she is a plant, he is a hunter and she is a pray. They are not equal, so, there is no love bondage between her and him, but power bondage, between a powerful and a vulnerable person.

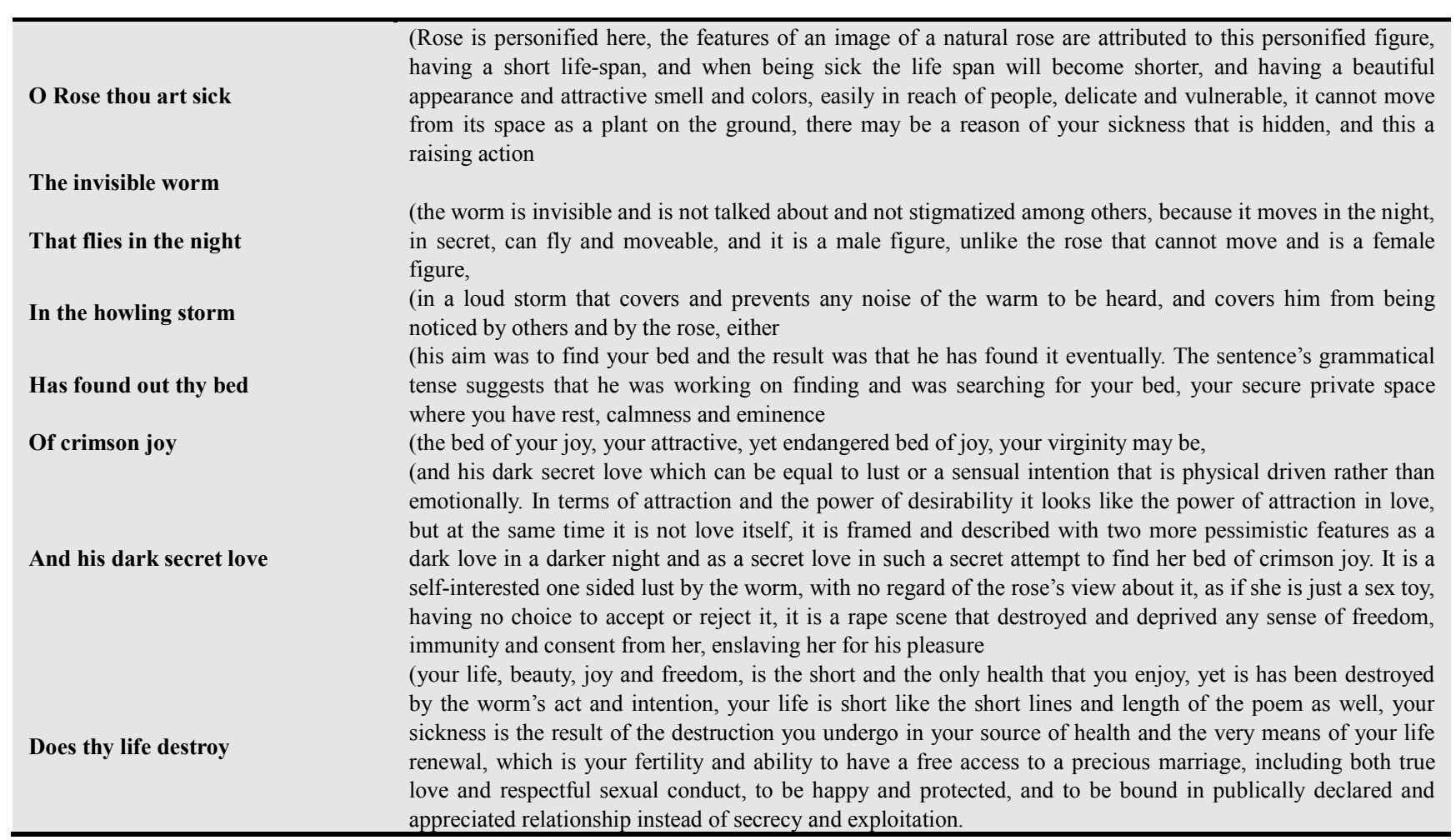

\section{LITTLE GIRL WAKES EARLY}

Robert Penn Warren

Remember when you were the first one awake, the first To stir in the dawn-curdled house, with little bare feet Cold on boards, every door shut and accurst,

And behind shut doors no breath perhaps drew, no heart beat.

You held your breath and thought how all over town Houses had doors shut, and no whisper of breath sleeping, And that meant no swinging, nobody to pump up and down, No hide-and-go-seek, no serious play at housekeeping.

So you ran outdoors, bare feet from the dew wet, And climbed the fence to the house of your dearest friend, And opened your lips and twisted your tongue, all set To call her name -- but the sound wouldn't come in the end,

For you thought how awful, if there was no breath there For answer. Tears start, you run home, where now mother, Over the stove, is humming some favorite air.

You seize her around the legs, but the tears aren't over,

And won't get over, not even when she shakes you -And shakes you hard -- and more when you can't explain.

Your mother's long dead. And you've leamed that when loneliness takes you

There's nobody ever to explain to -- though you try again and again.

The key words and images are (first one, awake, energy, move, warmth, in a cold house, early, bare feet on cold where ground no heat, doors as barriers and borders between two different phases, yet the same phases would be seen behind them and there is no change or difference, no breath, no heartbeat, no pulse of heart, houses as sources of warmth are all shut, may be no life, even no secret life, or possible life, no motion, except the girl's motion, no up and down, no change, no challenge, no joy, no game, no childish curiosity or spirit, no whisper, no swinging no movement, no secret, no mystery, no hide-and-go-seek, fence, friend, lips and tongue, no answer, tears, mother, seize mother around the legs, mother shakes the girl, no explanation from the girl's part, mother has died, there is a lesson learned, loneliness cannot be explained to anyone, but one may try and try to explain or talk about loneliness because it is not a physical need, it is a deep psychological need).

The final conclusion is that (there are some questions from the beginning of the poem, like; Which wake is there, why a little girl, from what does she wake, early in terms of what? It is physical, emotional, hardship of a young girl's loneliness and sorrow that they cannot explain or there is no one to listen to them. It is an experiential wake, opening eyes and senses, not to go far for her source of warmth and love.)The number of the stanzas, 5, may suggest the age of the little girl, either. She was with the mother, she left her mother searching for warmer or more intimate spaces, be within friends, but there was none. So, she came back crying, and not able to explain either. Although her language is not so expressive yet, her feeling is deeply influencing her. It is a stage of loneliness when feeling and experience are grown well, while still language is not, yet. However, even when growing older in terms of age, just because being lonely again, there is no way of explaining it, 
no one to listen, no one would care. It is a wake of unexpressed or unexplained loneliness, which is just cold and freezing as a real physical winter. She passes through a winter-like psychological state of mind in loneliness. She tries to tie herself round her mother's leg as a symbol of movement and warmth, but there was nothing. The girl was out to find someone to play with, to share life moments with, but she founds no one, so although she has her mother to tell her about that, she didn't, for she was sure that the mother is alone like her. This is what she learned from her mother's loneliness. Loneliness is hard, yet it is lived, rather than explained. So, this poem is about the prior loneliness of women at that age that this little girl discovers and awakes on in an early age. The girl's wake is the realization of the hardship of the coming loneliness coming to shake her in this society, not only the hard shakes by her mother. It is a woman wake, rather than a shake the mother may make.

Your body is cold, yet you are warm within, vigorous, energetic, motional,

You had a mother, now you have no one, when they leave you alone, you were crying and trying to explain to her, warmth of mother is within, home is mother's warm territory,

Open, play with friend, love, cry for loneliness, need to explain reason of your cry, what would reason do for your experiential or emotional early wake?

Your mother as a source of your love, heat and motion is inside, the home and the heart and the heat all are inside, why do you try to open the door and go out to find one? When not telling the mother why do you cry, whom do you explain to, later?

\section{THE MIRROR \\ Sylvia Plath}

I am silver and exact. I have no preconceptions.

Whatever I see, I swallow immediately.

Just as it is, unmisted by love or dislike.

I am not cruel, only truthful -

The eye of a little god, four-cornered.

Most of the time I meditate on the opposite wall.

It is pink, with speckles. I have looked at it so long

I think it is a part of my heart. But it flickers.

Faces and darkness separate us over and over.

Now I am a lake. A woman bends over me.

Searching my reaches for what she really is.

Then she turns to those liars, the candles or the moon.

I see her back, and reflect it faithfully.

She rewards me with tears and an agitation of hands.

I am important to her. She comes and goes.

Each morning it is her face that replaces the darkness.

In me she has drowned a young girl, and in me an old woman

Rises toward her day after day, like a terrible fish.

The key words and images are (I, silver, exact, see, swallow, unmisted by love, dislike, no cruelty, eye of god, four-cornered, mediate on opposite wall, pink with speckles, look at it long, part of heart, flicker, faces and darkness, separate, over and over, lake, woman bends, searching what she is in me, liars, candles or moon, her back, reflect it, reward with tear and agitation of hands, importance, her face replaces darkness, young girl drowned, old woman rises toward her like a terrible fish)

As analysis and conclusion, the two parts of the poem would refer to the two images seen in front of a mirror. The mirror speaks in first person singular "I".I am confidential, and immediately hide secrets, not emotional, and not affected by emotions, I think deeply about the opposite wall, fixed, choice less, opposed to me without its choice. This pink room belongs to a woman I live with, may be the second beloved of a man, the man is darkness, or he is a lying and deceiving light, betraying woman with artificial love in his admiration to her appearance and her face, yet the woman is the same ugly one from the back view, where there may be a sensual connotation here about the back of her, as implying that whatever the face was the back would not show, whatever the beauty and admiration of beauty was psychologically different from a woman to another, the sensuality wouldcare about and seeks the same physical pleasure.

Later, the woman's face turns to other men, toward other faked external lights of men, convincing herself that she is more beautiful than what I show her on my face as a mirror. Although the wall's pink color is speckled and it is my permanent nature and I don't change, everyday this lady shows me herself differently, with changeable appearance. Love and warmth, but with dirt, meditate at my depth. I have been here for a long time, in the same room, the room has the same color for a long time, no change, my heart swallowed that, because of my heart's trait, but the faces and darkness of my context don't let my heart rest on this color and stable wall. As a barrier, darkness prevents me from enjoying this trait, which is the only identity I have so long so far. The context denies me having such definite trait, and faces show me themselves, unknown or changed or masked faces, not only one. I do not have any privacy, as if in a hotel, I want to swallow those faces, into my heart but they separate me from having long lasting trait, love, heart, truth. So, those faces flicker my heart and identity.

My face is like surface of water of a lake, a lady approaches me, bends to see her reality, then seeks liars and lights and media, I swallow her tears and agitation, which both are bitter. She does not want to confess her age, getting older, being exploited, being dishonestly treated, because she believes in liars not me, when getting old those liars will show her a bitter truth that she would not expect. There are liar lights of flattering men, or may be of media, in and outside the room where I am, ordinary and famous ones. (This woman may be another wife of the poet'shusband). Here, the light lies to my face, I see her back, she cries, tears come on me, and her hands in grief and agitation to do something but she cannot, she wants to know the lights and moon by me, repeatedly visits me, inquires me about her reality and truth, I am telling her her own truth, she searches for a younger girl day by day, she expects a nice fish coming out of my lake, but every day she grows elder and a terrible fish will come out, which is herself. 


\subsection{One Perfect Rose by Dorothy Parker1893 - 1967}

The key words and images are (single, flower, me, tenderly chosen messenger, deep, pure, wet, one, perfect, rose, language of flower, fragile leaves enclosing his heart, love, amulet, no one, limousine, you, question mark, negation, my luck is to get one perfect rose.

As analysisandconclusion, a single flower turns to become one perfect rose in the poet's imaginative judgment or evaluation. The three stanzas of poem would suggest an argument, as the first part is the introduction, the second is the support, and the third is the conclusion. The title and the refrain repeat and tie the whole parts like a circle.The flower is a speaking messenger, living and still dew wet.

The speaker understands the rose's language, communicates with it, and gets the message; "My fragile leaves, his heart enclose."Itencloses a box of jewel.So, the treasure is more valuable than the box itself, and it is just a messenger, or a means to hide the valuable heart, not to be discovered or seen. What is deeper is that even the heart itself is not the treasure, but the love it encloses. So, it is twice enclosed and that's why it is a one unique perfect rose, not any other rose people would imagine. The perfection is not in the type and shape of the rose, but in its enclosure, or what it carries within. Language of feeling and experience is a common and communicable language between the sender and the receiver. That's why it is clear to her what he means by the rose. Till now, the speaker speaks to the rose and its enclosure.

Then the speaker turns to an audience or a fellow with her, that would ask the speaker and suppose; "Why is it no one ever sent me yet... One perfect limousine?" Here, the speaker refuses the question or the supposition by the audience, and says, "Ah, no" and tells about her preference "it's always my luck to get... One perfect rose" and accepts this everlasting luck, because it was unique.

A single flow'r he sent me, since we met.

All tenderly his messenger he chose;

Deep-hearted, pure, with scented dew still wet--

One perfect rose.

I knew the language of the floweret;

"My fragile leaves," it said, "his heart enclose."

Love long has taken for his amulet

One perfect rose.

Why is it no one ever sent me yet

One perfect limousine, do you suppose?

Ah no, it's always just my luck to get

One perfect rose.

To sum up, the problem of lack of understanding of poetry has a long history. This issue could be addressed via the technique of visualizing of imagination by the teacher in the classroom, as this will assist the majority of the students to understand the sense and the beauty of the poem. When a piece of poem cannot be expressed via words, then images can have a very positive role in this respect and can change the attitude of the students towards the poem as well as the teacher in a very positive way.

\section{Literature Reviews and Source Collection}

A Cognitive Approach to John Donne's Songs and Sonnets, Michael A. Winkelman, New York, 2013.

An Analysis of Poetic Thinking, Max Rieser, 1969.

An Introduction to Visual Culture, Nicholas Mirzoeff, Routledge, London and New York. 1999.

Children Write Poetry a Creative Approach, Flora J. Arnstein, New York, 1967.

Configurations a Topomorphical Approach to Renaissance Poetry, Maren-Sofie Rostvig, Stockholm, 1994

Critical Theory, a reader for Literary and Cultural Studies, Robert Dale Parker. Oxford University Press. New York, Oxford. 2012.

Impersonality, Sharon Cameron, Chicago and London, 2007.

Interpreting Visual Culture, Explorations in the Hermeneutics of the Visual, Ian Heywood and Barry Sandywell. Routledge, Londn. 1999.

Kenneth Burke, Literature as Equipment for Living.

Knowledge Visualization Background, Martin J. Eppler. Switzerland. 2013.

On English Poetry, Robert Grave, London, 1921.

Poetry as Experienced. John Dewy

Poets, Poem, Poetry by Helen Vendler

Practical Stylistics an Approach to Poetry, H. G. Widdowson, 1992.

Recurrence and a Three-Modal Approach to Poetry, Walter A. Kock, Paris, 1966.

Seen and Unseen, Visual Culture, Sociology and Theory, Kleran Flanagan. Palgrave Macmillan, United Kingdom. 2004.

The Poet's Vision and Magic of Words an Approach to Iqbal's Poetry, Muhammad Iqbal, M. A. Lahore, 1978.

The Poetry of Rafael Alberti a Visual Approach, Robert C. Manteiga, London, 1978.

The Reader and the Text. Wolfgang Isere

The Visual Culture Reader, Nicholas Mirzoeff, Routledge, London and New York. 1998.

Vision and Visuality, Hal Foster, Dia Art Foundation, Washington. 1988.

Visual Cultures and Critical Theory, Patrick Fuery and Kelli Fuery, London, 2003.

\section{References}

[1] Burke, Kenneth. The philosophy of literary form: Studies in symbolic action. Vol. 266.University of California Pr, 1974.

[2] Cooper, Monica Wengrowicz. "Poetry and Scientific Exposition: An Analysis of Two Forms of Symbolic Representation."Journal of Aesthetic Education36.1 (2002): 86-99. Print.

[3] Eric J. Sundquist. "The Humanities and the National Interest."American Literary History24.3 (2012): 590-607. Print. 
[4] GILES, PAUL. "Greil Marcus and Werner Sollors (Eds.), A New Literary History of America (Cambridge, MA: Harvard University Press, 2009, £36.95). Pp. xxvii+1095.Isbn 9780 67403594 2."Journal of American Studies 44.3 (2010): 627-8. Print.

[5] Le Menager, Stephanie, and Stephanie Foote."The Sustainable Humanities."PMLA127.3 (2012): 572-578.
[6] Michelle Ty. "On the Cognitive Turn in Literary Studies." Qui Parle: Critical Humanities and Social Sciences19.1 (2010): 205-219. Project MUSE. Web. 11 Dec. 2013. $<\mathrm{http}: / /$ muse.jhu.edu/>. 